Open Access

\title{
Multifunctional Antioxidant Activities of Alkyl Gallates
}

\author{
Isao Kubo*, Noriyoshi Masuoka, Tae Joung Ha, Kuniyoshi Shimizu and Ken-ichi Nihei
}

Department of Environmental Science, Policy and Management, University of California, Berkeley, California 947203114, USA

\begin{abstract}
A series $\left(\mathrm{C}_{1}\right.$ to $\left.\mathrm{C}_{16}\right)$ of alkyl gallates was tested for their antioxidant activity for food protection and human health. One molecule of alkyl gallate, regardless of alkyl chain length, scavenges six molecules of 1,1-diphenyl-2picrylhydrazyl (DPPH). Alkyl gallates inhibited the linoleic acid peroxidation catalyzed by soybean lipoxygenase-1 (EC 1.13.11.12, Type 1) without being oxidized. The progress curves for enzyme reactions were recorded by both spectrophotometric and polarographic methods and the inhibitory activity was a parabolic function of their lipophilicity $(\log P)$ and maximized with alkyl chain length between $\mathrm{C}_{12}$ and $\mathrm{C}_{16}$. Tetradecanyl $\left(\mathrm{C}_{14}\right)$ gallate exhibited the most potent inhibition with an $\mathrm{IC}_{50}$ of $0.06 \mu \mathrm{M}$. The inhibition kinetics of dodecyl gallate $\left(\mathrm{C}_{12}\right)$ revealed competitive and slow-binding inhibition. Alkyl gallates chelate transition metal ions and this chelation ability should be of considerable advantage as antioxidants. Additionally, gallic acid was found to inhibit superoxide anion generated by xanthine oxidase (EC 1.1.3.22) but did not inhibit enzymatically catalyzed uric acid formation.
\end{abstract}

Key Words: Antioxidant activity, alkyl gallates, multifunction, scavenger, soybean lipoxygenase-1, xanthine oxidase, antimicrobial activity.

\section{INTRODUCTION}

Antioxidants in foods normally refer to substances that can inhibit fatty acid autoxidation. The major antioxidants are metal chelators (preventive) and chain-breaking antioxidants (sacrificial) acting as hydrogen atom donors [1, 2]. Propyl, octyl and dodecyl (lauryl) gallates are currently permitted for use as antioxidant additives in food [3]. Hence, the previous studies usually emphasized their scavenging activity to use them as antioxidant additives in food. In addition to use them as antioxidant activities, we recently proposed that various multifunctional food additives such as a series of alkyl gallates, can be designed by selection of appropriate head and tail portions [4] since the balance of these two is related to many biological activities. However, the rationale for this observation, especially the role of the hydrophobic portion, is still poorly understood. The head and tail structures are synthetically easily accessible as an ester and therefore the construction of a wide range of structurally diverse multifunctional mimics are available for evaluation. However, selection of head and tail building blocks need to be concerned not only for food protection but also for their benefits to human health after their consumption. This prompted us to design antioxidative antimicrobial agents as an example [5]. For food protection, antioxidant additives acting in variety of ways including direct quenching of reactive oxygen species, inhibition of enzymes involved in the production of the reactive oxygen species, and chelation of low valent metals are needed in addition to antimicrobial

*Address correspondence to this author at the Department of Environmental Science, Policy and Management, University of California, Berkeley, California 94720-3114, USA; Tel: +1-510-643-6303; Fax: +1-510-6430215; E-mail: ikubo@berkeley.edu activity. Lipid peroxidation is one of the major factors in deterioration during the storage and processing of foods. For example, the oxidation of membrane lipids is implicated in the development of off-flavors [6], loss of fresh meat color [7], and the formation of harmful lipid peroxidation products [8] in muscle foods. Addition of antioxidants has become popular as a means of increasing the shelf life of food products and of improving the stability of lipid-containing foods by preventing loss of sensory and nutritional quality [9]. In living systems, the oxidation of unsaturated fatty acids in biological membranes leads to a decrease in the membrane fluidity and disruption of membrane structure and function $[10,11]$. Cellular damage due to lipid peroxidation causes serious derangements, such as ischemia-reperfusion injury, coronary arteriosclerosis, and diabetes mellitus $[12,13]$, and it is also associated with aging and carcinogenesis [14]. Hence, antioxidant development/use/selection needs to be concerned about all the processes mentioned previously. This prompted us to further examine various antioxidative activities of a series of alkyl gallates as an example.

\section{RESULTS}

Alkyl gallates (1-17) (see Fig.1 for structures) act as antioxidants in a variety ways that include quenching reactive oxygen species, inhibiting various prooxidant enzymes involved in the production of the reactive oxygen species, and chelating divalent metal ions such as $\mathrm{Fe}^{2+}$ and $\mathrm{Cu}^{2+}$. Hence, alkyl gallates can be defined as multifunctional antioxidants. Their diverse antioxidant activities are directly or indirectly explained by their head and tail structural function, indicating that the alkenyl side chain is largely associated with the activity. The available data have been reported as the result of sporadic research, so it is time to review and summarize in one paper all what is currently known. 
<smiles>[R]OC(=O)c1cc(O)c(O)c(O)c1</smiles>

$$
\begin{aligned}
& \text { 1: } \mathrm{R}=\mathrm{H} \\
& \text { 2: } \mathrm{R}=\mathrm{CH}_{3} \\
& \text { 3: } \mathrm{R}=\mathrm{CH}_{2} \mathrm{CH}_{2} \mathrm{CH}_{3} \\
& \text { 4: } \mathrm{R}=\mathrm{CH}_{2}\left(\mathrm{CH}_{2}\right)_{4} \mathrm{CH}_{3} \\
& \text { 5: } \mathrm{R}=\mathrm{CH}_{2}\left(\mathrm{CH}_{2}\right)_{6} \mathrm{CH}_{3} \\
& \text { 6: } \mathrm{R}=\mathrm{CH}_{2}\left(\mathrm{CH}_{2}\right)_{7} \mathrm{CH}_{3} \\
& \text { 7: } \mathrm{R}=\mathrm{CH}_{2}\left(\mathrm{CH}_{2}\right)_{8} \mathrm{CH}_{3} \\
& \text { 8: } \mathrm{R}=\mathrm{CH}_{2}\left(\mathrm{CH}_{2}\right)_{9} \mathrm{CH}_{3} \\
& \text { 9: } \mathrm{R}=\mathrm{CH}_{2}\left(\mathrm{CH}_{2}\right)_{10} \mathrm{CH}_{3} \\
& \text { 10: } \mathrm{R}=\mathrm{CH}_{2}\left(\mathrm{CH}_{2}\right)_{12} \mathrm{CH}_{3}
\end{aligned}
$$

14:<smiles>CC1CCC(C(C)C)C(C#P)C1</smiles>
16: $\mathrm{R}=$

15: $\mathrm{R}=$<smiles>CC1CC2CCC1(C)C2(C)C</smiles><smiles>CC(C)=CCCC=C(C=C=[Te])CCC=[Te]</smiles><smiles>[R1]OC(=O)c1cc([R4])c([R3])c([R])c1</smiles>

11: $\mathrm{R}_{1}=\mathrm{CH}_{2}\left(\mathrm{CH}_{2}\right)_{10} \mathrm{CH}_{3}, \mathrm{R}_{2}=\mathrm{R}_{3}=\mathrm{OH}, \mathrm{R}_{4}=\mathrm{H}$

12: $\mathrm{R}_{1}=\mathrm{CH}_{2}\left(\mathrm{CH}_{2}\right)_{10} \mathrm{CH}_{3}, \mathrm{R}_{2}=\mathrm{R}_{4}=\mathrm{OH}, \mathrm{R}_{3}=\mathrm{H}$

13: $\mathrm{R}_{1}=\mathrm{CH}_{2}\left(\mathrm{CH}_{2}\right)_{10} \mathrm{CH}_{3}, \mathrm{R}_{2}=\mathrm{R}_{4}=\mathrm{H}, \mathrm{R}_{3}=\mathrm{OH}$

Fig. (1). Chemical structures of gallic acids and related compounds.

\subsection{Scavenging Activity}

For food protection, alkyl gallates are useful as antioxidative antimicrobial agents. Gallic acid and its methyl, ethyl, propyl and $n$-butyl esters were previously reported to scavenge the 1,1-diphenyl-2-picrylhydrazyl (DPPH) radical $[15,16]$ but these studies were not comprehensive. Hence, the radical scavenging activity on the DPPH radical, which can be measured as decolorizing activity following the trapping of the unpaired electron of DPPH, was examined first. The reaction progress absorbance of the mixture is monitored at $517 \mathrm{~nm}$ for $20 \mathrm{~min}$ and the results are listed in Table 1. Gallic acid and its series $\left(C_{1}-C_{12}\right)$ of alkyl esters showed almost equally potent radical scavenging activity on DPPH radical. One molecule of alkyl gallates scavenges six DPPH molecules. Thus, alkyl gallates are oxidized three times by DPPH within $20 \mathrm{~min}$ as illustrated (Fig. 2). The scavenging activity does not correlate with the hydrophobic alkyl chain length. This is consistent with the previous report
[17]. Hence, all the alkyl gallates can be used as scavenging antioxidants and selection of the tail portion seems to be flexible. On the other hand, their antimicrobial activity is dependent on the chain length and a broad antimicrobial spectrum should be preferred for food protection. Nonyl gallate $\left(\mathrm{C}_{9}\right)(6)$ showed the most potent and broad spectrum $[18,19]$ followed by octyl gallate $\left(C_{8}\right)(5)$ [20]. Dodecyl (lauryl) gallate $\left(\mathrm{C}_{12}\right)$ (9) was found to be effective on Gram-positive bacteria [21]. Since both octyl gallate and dodecyl gallate are currently permitted for use as antioxidant additives in food [3], the next experiment was centered on these two gallates.

Table 1. Scavenging Activity of Gallic Acid and Its Esters

\begin{tabular}{|c|c|}
\hline Gallates Tested & DPPH Consumption $^{\text {a }}$ \\
\hline \hline Gallic acid (1) & $6.51 \pm 0.30$ \\
\hline $\mathrm{C}_{1}(\mathbf{2})$ & $6.34 \pm 0.12$ \\
\hline $\mathrm{C}_{3}(\mathbf{3})$ & $6.02 \pm 0.17$ \\
\hline $\mathrm{C}_{6}(\mathbf{4})$ & $5.74 \pm 0.22$ \\
\hline $\mathrm{C}_{8}(\mathbf{5})$ & $6.09 \pm 0.14$ \\
\hline $\mathrm{C}_{9}(\mathbf{6})$ & $5.84 \pm 0.17$ \\
\hline $\mathrm{C}_{10}(\mathbf{7})$ & $6.02 \pm 0.18$ \\
\hline $\mathrm{C}_{12}(\mathbf{9})$ & $7.28 \pm 0.54$ \\
\hline Menthyl (14) & $6.71 \pm 0.03$ \\
\hline Bornyl (15) & $6.61 \pm 0.20$ \\
\hline$\alpha-$ Tocopherol & $2.65 \pm 0.28$ \\
\hline
\end{tabular}

a) number of scavenged DPPH molecules per one test molecule.

The trolox equivalent antioxidant capacity (TEAC) assay is based on the scavenging of the 2,2'-azinobis-(3ethylbenzothiazoline-6-sulfonic acid) (ABTS) radical (ABTS -) converting it into a colorless product. The degree of decolorization induced by a compound is related to that induced by trolox, giving the TEAC value. The TEAC value for gallic acid was $3.0 \mathrm{mM}$ which is appropriately the same antioxidant activity as myricitin $(3.1 \mathrm{mM})$, although esterification of the carboxylate decreases the effectiveness [22]. This activity of gallic acid is much weaker compared with its scavenging activity on DPPH radical by several orders of magnitude.

Lipid peroxidation is well known to be one of the major factors in deterioration of foods during storage and processing, because it can lead to the development of unpleasant rancid or off flavors as well as potentially toxic end products $[23,24]$. Lipid peroxidation is a typical free radical oxidation and proceeds via a cyclic chain reaction [25] and linoleic acid is specifically the target of lipid peroxidation. Effect of alkyl gallates on autoxidation of linoleic acid was tested by the ferric thiocyanate method as previously described [26]. In a control reaction, the production of lipid peroxide increased almost linearly during 5 days of incubation. $\alpha$-Tocopherol, also known as vitamin E, inhibited the linoleic acid peroxidation almost $50 \%$ at $30 \mu \mathrm{g} / \mathrm{mL}$. Both octyl gallate and dodecyl gallate almost completely inhibited this 
oxidation at the same concentration, indicating that both gallates are more potent linoleic acid peroxidation inhibitors than $\alpha$-tocopherol.

\subsection{Inhibition of Prooxidant Enzymes}

\subsubsection{Lipoxygenase}

Lipoxygenases (EC 1.13.11.12) are suggested to be involved in the lipid peroxidation [27]. Hence, lipoxygenase inhibitors should have broad applications [28]. Soybean lipoxygenase- 1 is known to catalyze the oxygenation of polyenoic fatty acids containing a $(1 Z, 4 Z)$-pentadiene system such as linoleic acid and linolenic acid to their 1-hydroperoxy- $(2 E, 4 Z)$-pentadiene products. In plants, the primary dioxygenation product is $13(S)$-hydroperoxy-9Z,11Eoctadienoic acid (13-HPOD) [29]. Hence, the enzyme assay was usually performed using a UV spectrophotometer to detect the increase at $234 \mathrm{~nm}$ associated with the $(2 E, 4 Z)$ conjugated double bonds newly formed in the product but not the substrate. In many previous reports, the data were obtained at $\mathrm{pH} 9$ since soybean lipoxygenase-1 had its optimum $\mathrm{pH}$ at 9.0 [30], but the absorption at $234 \mathrm{~nm}$ suffered from unstable baseline activity of unknown origin attributable to the presence of alkyl gallates at $\mathrm{pH} 9.0$. This pseudoactivity of the blank control had to be subtracted from activity of the enzyme assay, making precise measurements difficult. Hence, lipoxygenase activity was measured as described previously [31] in Tris- $\mathrm{HCl}$ buffer (0.1 M, $\mathrm{pH} 8.0)$ by the increase in absorbance at $234 \mathrm{~nm}$ from 30 to $90 \mathrm{sec}$ after addition of the enzyme, using linoleic acid $(18 \mu \mathrm{M})$ as a substrate. The results are listed in Table 2.

The same series of alkyl gallates (2-9) were found to inhibit the linoleic acid peroxidation catalyzed by soybean lipoxygenase- 1 without being oxidized. The inhibitory activity was a parabolic function of their lipophilicity and maximized with alkyl chain length between $C_{12}$ and $C_{16}$. Tetradecanyl $\left(\mathrm{C}_{14}\right)$ gallate exhibited the most potent inhibition with an $\mathrm{IC}_{50}$ of $0.06 \mu \mathrm{M}$, followed by dodecyl $\left(\mathrm{C}_{12}\right)$ gallate with an $\mathrm{IC}_{50}$ of $0.07 \mu \mathrm{M}$ (Fig. 3). Octyl gallate $\left(\mathrm{C}_{8}\right)$ was previously described to inhibit this enzymatically catalyzed oxidation with an $\mathrm{IC}_{50}$ of $1.3 \mu \mathrm{M}$. The inhibition kinetics analyzed by Lineweaver-Burk plots indicates that octyl gallate is a competitive inhibitor and the inhibition constant $\left(K_{\mathrm{I}}\right)$ was obtained as $0.54 \mu \mathrm{M}$ (Fig. 4) [31]. The inhibition of soybean lipoxygenase-1 of longer alkyl gallates is reversible but in<smiles>[R]OC(=O)C1=CC(O)=C(O)C(=O)C1([Y8])O</smiles><smiles>[R]OC(=O)c1cc(O)c(O)c(O)c1O</smiles><smiles>[R]OC(=O)C1=CC(=O)C(O)=C(O)C1=O</smiles><smiles>[R]OC(=O)C1=C(O)C(=O)C(O)=C(O)C1=O</smiles>

Fig. (2). One molecule of alkyl gallate, regardless of its alkyl chain length, can be oxidized three times by DPPH radical into the corresponding quinone.

Table 2. $\quad \mathrm{IC}_{50}, K_{\mathrm{I}}, \log P$ Values and Inhibition Type of Alkyl Gallate against Soybean Lipoxygenase-1

\begin{tabular}{|c|c|c|c|c|}
\hline \multirow{2}{*}{ Gallates Tested } & \multicolumn{2}{|c|}{$\mu \mathrm{M}$} & \multirow{2}{*}{$\log P$} & \multirow{2}{*}{ Inhibition Type } \\
\hline & $\mathrm{IC}_{50}{ }^{a}$ & $K_{\mathrm{I}}$ & & \\
\hline $\mathrm{C}_{1}(\mathbf{2})$ & $>200$ & - & 0.69 & - \\
\hline $\mathrm{C}_{3}(\mathbf{3})$ & 82.6 & 39.9 & 1.27 & Competitive \\
\hline $\mathrm{C}_{6}(\mathbf{4})$ & 8.7 & 4.40 & 2.76 & Competitive \\
\hline $\mathrm{C}_{8}(\mathbf{5})$ & 1.3 & 0.54 & 3.60 & Competitive \\
\hline $\mathrm{C}_{9}(6)$ & 0.6 & 0.21 & 4.01 & Mixed \\
\hline $\mathrm{C}_{10}(7)$ & 0.15 & $-{ }^{b}$ & 4.43 & Mixed \\
\hline $\mathrm{C}_{11}(\mathbf{8})$ & 0.12 & - & 4.85 & - \\
\hline $\mathrm{C}_{12}(\mathbf{9})$ & 0.07 & - & 5.27 & Slow binding \\
\hline $\mathrm{C}_{14}(\mathbf{1 0})$ & 0.06 & - & 6.10 & Slow binding \\
\hline NDGA & 0.19 & - & - & - \\
\hline
\end{tabular}

${ }^{a}$ Assay condition of [E]: $0.141 \mu \mathrm{g} / \mathrm{mL} ;[\mathrm{S}]: 18 \mu \mathrm{M}$; Buffer: $0.1 \mathrm{M}$ Tris- $\mathrm{HCl}$ (pH8.0). 
combination with their ability to disrupt the active site competitively and to interact with the hydrophobic portion surrounding near the active site. In the case of tetradecanyl gallate, the enzyme quickly and reversibly binds this gallate and then its tetradecanyl group undergoes a slow interaction with the hydrophobic domain (Fig. 5, panel A). Apparently, the alkyl chain length is significantly related to the soybean lipoxygenase- 1 inhibitory activity.

To further investigate the inhibitory effect of tetradecyl gallate (10) on dioxygenase enzyme, we assayed soybean lipoxygenase-1 activity with the inhibitor. Soybean lipoxygenase-1 showed time-dependent inhibition in the presence of dodecyl gallate (Fig. 5, panel A). Increasing tetradecyl gallate concentrations led to the decrease in both the initial velocity $\left(v_{\mathrm{i}}\right)$ and the steady-state rate $\left(v_{\mathrm{s}}\right)$ in the progress curve. The progress curves obtained using various concentrations of the inhibitors were fitted to eq 1 to determine $v_{\mathrm{i}}, v_{\mathrm{s}}$, and $k_{\text {obs. }}$. The plot for $k_{\text {obs }}$ versus [I] are shown in panel $\mathbf{B}$ in Fig. (5). That plot showed a hyperbolic dependence on the concentration of the tetradecyl gallate, so the inhibition of lipoxygenase-1 by tetradecyl gallate followed a mechanism as the one illustrated below. The kinetic parameters, $k_{5}, k_{6}$, and $K_{\mathrm{i}}^{\text {app }}$ were derived from the plots by fitting the results to eq 2 . Thus, analysis of data according to eq 2 yielded the following values: $k_{5}=9.1 \times 10^{-3} \mathrm{~s}^{-1}, k_{6}=1.5 \times 10^{-3} \mathrm{~s}^{-1}$, $K_{\mathrm{i}}^{\text {app }}=0.48 \mu \mathrm{M}$. The kinetic model can be written as:

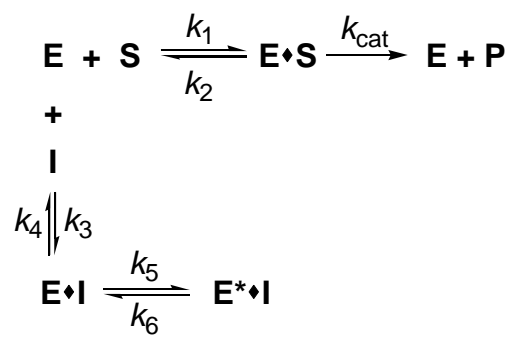

where E, S, I, and P denote enzyme, substrate, inhibitor (alkyl gallate) and product (13-HPOD), respectively. ES, EI and $E^{*} I$ are respective complexes. Because $k_{5}$ is greater than $k_{6}$ the enzyme first quickly and reversibly binds with tetradecyl gallate and then undergoes a slow interaction of tetradecyl group with the hydrophobic portion near the active site.

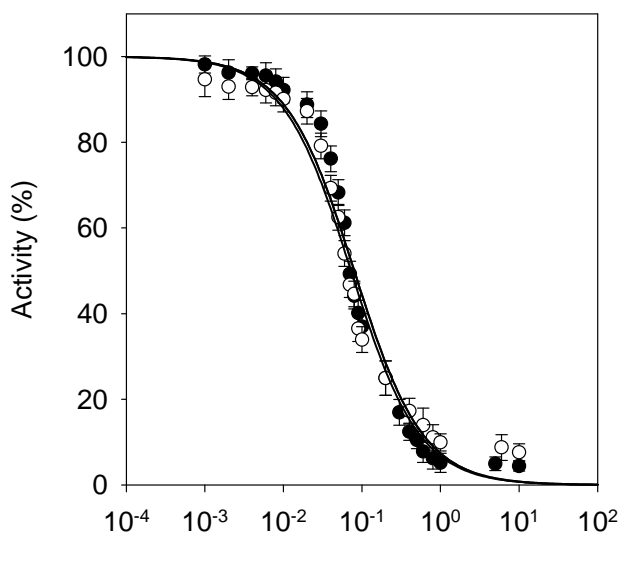

[l], $(\mu \mathrm{M})$

Fig. (3). Effects of dodecyl gallate (closed circle: 9) and tetradecyl gallate (open triangle: 10) on the activity of soybean lipoxygenase-1 for the catalysis of linoleic acid at $25^{\circ} \mathrm{C}$.

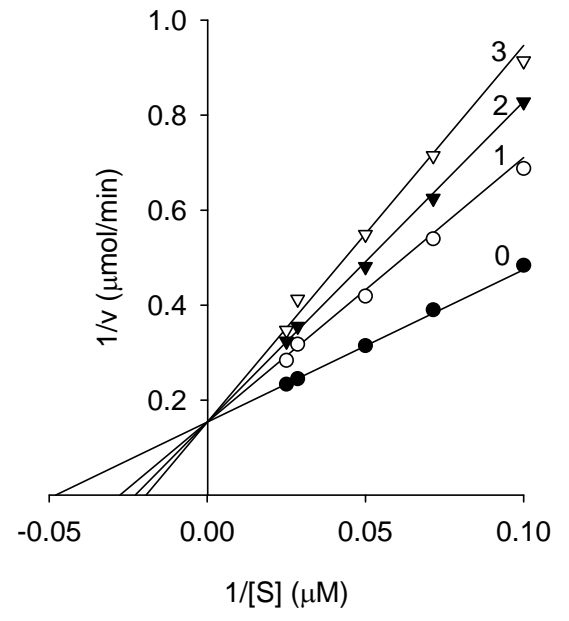

Fig. (4). Lineweaver-Burk plots of 13-HPOD generation by soybean lipoxygenase-1 in the presence of octyl gallate $(5)$ at $25^{\circ} \mathrm{C}$, $\mathrm{pH}$ 8.0. Concentrations of octyl gallate for curves $0-3$ were $0,0.4$, 0.6 , and $0.8 \mu \mathrm{M}$, respectively.
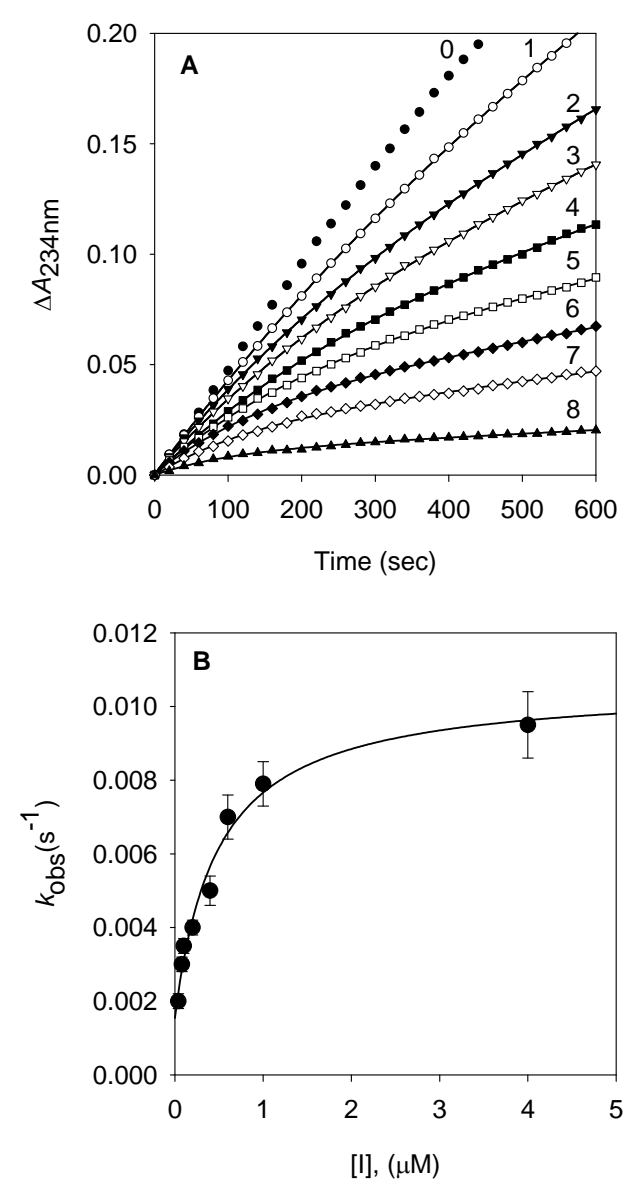

Fig. (5). Time-dependent inhibition of soybean lipoxygenase-1 in the presence of tetradecyl gallate (10). (A) Conditions were as follows: $40 \mu \mathrm{M}$ linoleic acid, $1.3 \mathrm{nM}$ lipoxygenase-1, and concentrations of tetradecyl gallate for curves $0-8$ were $0,0.04,0.08,0.1,0.2$, $0.4,0.6,1.0$, and $4.0 \mu \mathrm{M}$. The $k_{\mathrm{obs}}$ values at each inhibitor concentrations were determined by fitting the data to eq 1. (B) Dependence of the values for $k_{\mathrm{obs}}$ on the concentration of tetradecyl gallate. The $k_{\text {obs }}$ values, determined in panel $\mathbf{A}$, were fitted to eq 2 . 
Dodecyl 3,4-dihydroxybenzoate (11) inhibited linoleic acid peroxidation catalyzed by soybean lipoxygenase-1, whereas both dodecyl 3,5-dihydroxybenzoate (12) and dodecyl 4-hydroxybenzoate (13) showed little inhibitory activity, indicating that certain head portions are needed to elicit the inhibitory activity. Thus, catechol moiety seems to be important to elicit potent soybean lipoxygenase-1 inhibitory activity as a hydrophilic head portion $[28,32]$. In addition, menthyl gallate (14), bornyl gallate (15) and decahydro-2naphthyl gallate (16) also inhibited linoleic acid peroxidation catalyzed by soybean lipoxygenase-1, indicating that the hydrophobic tail portion seems to be flexible. As mentioned above, alkyl gallates were found to possess equally potent radical scavenging activity on DPPH radical. Apparently, intermediate free radicals are formed during the catalytic cycle of lipoxygenases [33], but they remain tightly bound at the active site, thus not being accessible for free radical scavengers. In summary, alkyl gallates appear to combine both lipoxygenase inhibitory activity and free radical scavenging property in one agent and thus constitute effective antioxidants.

\subsubsection{Xanthine Oxidase}

The one-electron reduction products of $\mathrm{O}_{2}$, superoxide anion $\left(\mathrm{O}_{2} \cdot{ }^{-}\right)$, and subsequently hydrogen peroxide $\left(\mathrm{H}_{2} \mathrm{O}_{2}\right)$ and hydroxyl radical (HO-) derived from $\mathrm{H}_{2} \mathrm{O}_{2}$ and $\mathrm{O}_{2} \cdot{ }^{-}$, actively participate in the initiation of lipid peroxidation. Several oxidative enzymes in the human body produce free radicals. For example, xanthine oxidase produces the $\mathrm{O}_{2}{ }^{-}-$radical as a normal product [34]. In the control, superoxide anion reduces yellow nitroblue tetrazolium to blue formazan, so the generation of superoxide anion by the enzyme can be detected by measuring of the absorbance at $560 \mathrm{~nm}$ of formazan produced. Among the alkyl gallates tested, gallic acid was the most effective in scavenging superoxide anion generated by xanthine oxidase with an $\mathrm{IC}_{50}$ of $2.6 \mu \mathrm{M}$. The inhibition kinetics analyzed by LineweaverBurk plots shows that gallic acid is a mixed type inhibitor (Fig. 6) and the inhibition constants, $K_{\mathrm{I}}$ and $K_{\mathrm{IS}}$ were obtained as $1.5 \pm 0.2$ and $2.9 \pm 0.3 \mu \mathrm{M}$. Xanthine oxidase is a molybdenum-containing enzyme and converts xanthine to uric acid. This enzyme-catalyzed reaction is known to proceed via transfer of an oxygen atom to xanthine from the molybdenum center. Hence, formation of uric acid was also measured. As a result, gallic acid did not inhibit xanthine oxidase up to $200 \mu \mathrm{M}$, indicating that its potent antioxidant activity comes from scavenging superoxide radicals or modification of xanthine oxidase. Xanthine oxidase catalyzed formation of superoxide anion or hydrogen peroxide and uric acid but the reduced oxidase only catalyzed formation of hydrogen peroxide and uric acid [35]. As the inhibition activity of superoxide anion by gallic acid was stronger than the scavenging activity of superoxide anion generated by PMS-NADH, the inhibition activity by gallic acid should comes from excursively reductive (oxidative) modification of xanthine oxidase bound by gallic acid as following scheme [36]. The kinetic model can be written as:

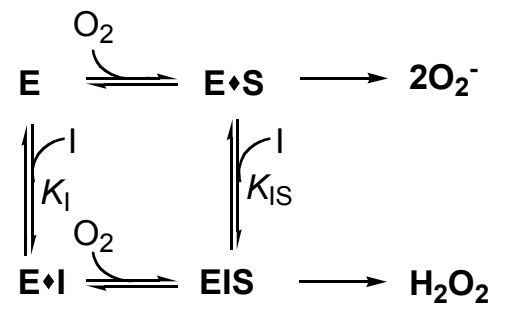

where E, S and I denote enzyme, substrate and inhibitor (alkyl gallate), respectively. ES, EI and EIS are respective complexes.

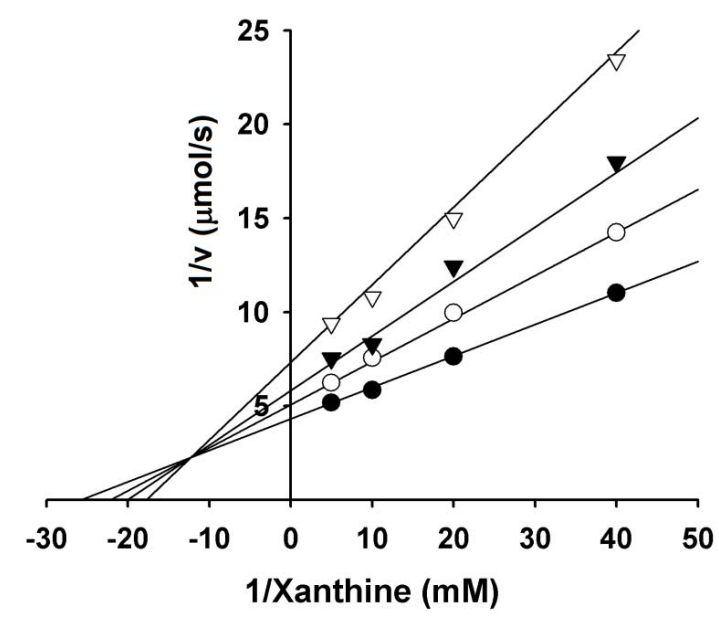

Fig. (6). Lineweaver-Burk plots of superoxide anion generation by xanthine oxidase in the presence of gallic acid (1) at $25^{\circ} \mathrm{C}, \mathrm{pH} 10.0$. Concentrations of gallic acid (1) for curves 0 -3 were $0,0.5,1.0$, and $2.0 \mu \mathrm{M}$, respectively.

Reaction of uric acid formation by xanthine oxidase is known to proceed via transfer of an oxygen atom to xanthine from the molybdenum center. X-ray crystallographic analysis of bovine milk xanthine oxidase indicated that one can model the binding of bicyclic substrates, e.g. with Phe 1009 perpendicular to the six-membered ring of xanthine and Phe 914 stacking flat on top of the substrate's five-membered ring, which would then be able to form a covalent bond with one of the molybdenum ligands [37]. As the present study indicated that alkyl gallates having long chains were predominantly competitive inhibitors for xanthine, we deduced that dodecyl gallate binds with Phe 1009 perpendicular to the pyrogallol moiety and Phe 914 stacking flat on top of the dodecyl group and the dodecyl chain tightly interacts with hydrophobic protein pocket to act as an anchor, which is necessary to inhibit uric acid formation, as illustrated in Fig. (7). To confirm this postulation, the effect of menthyl gallate (14) and bornyl gallate (15) on xanthine oxidase was examined. Neither compound inhibited uric acid formation, indicating that both can not bind to the xanthine binding site since the bulky cyclic monoterpene moieties, which are exposed on the other side of the molecules, cannot be well embraced by the hydrophobic protein pocket in xanthine binding site. 


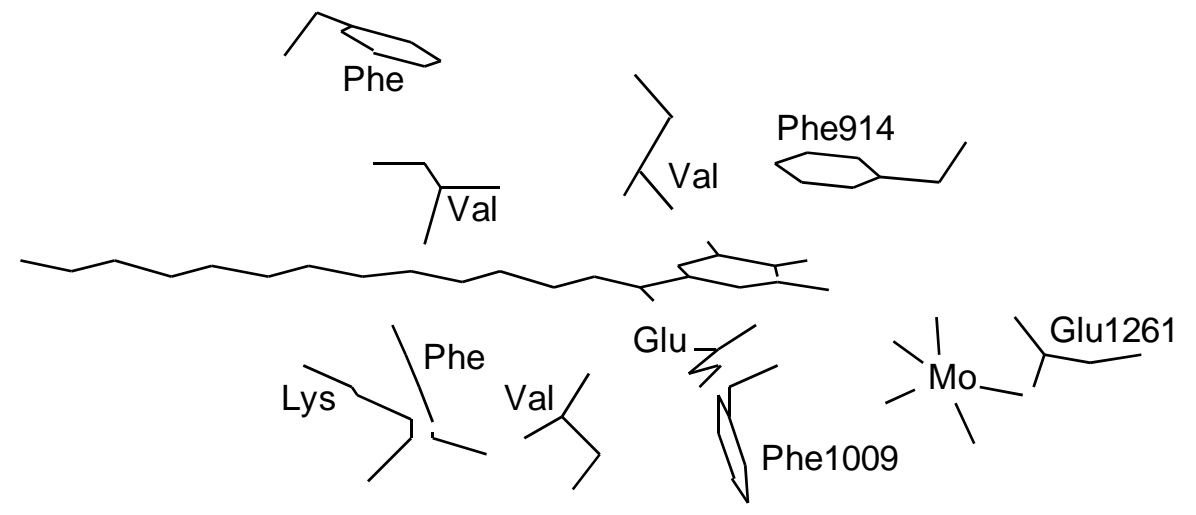

Fig. (7). Binding of dodecyl gallate to xanthine binding site in xanthine oxidase. Dodecyl gallate binds with Phe 1009 perpendicular to the pyrogallol moiety and Phe 914 stacking flat on top of the dodecyl group. Amino acid residues around the alkyl chain of dodecyl gallate indicate the hydrophobic protein pocket, and the alkyl chain interacts with them.

The inhibition of uric acid formation by alkyl gallates was further examined at different concentration of oxygen. Octyl gallate, decyl gallate and dodecyl gallate were also predominantly competitive inhibitors of oxygen. As these gallates bound to xanthine binding site of xanthine oxidase, it indicated that alkyl gallates could bind to another site, which may be oxygen binding site (or superoxide anion generation site), in xanthine oxidase.

To study the effect of gallic acid and alkyl gallates on superoxide anion generation, we examined the scavenging activity of superoxide anion by alkyl gallates since the activity was well known. Superoxide anion was nonenzymatically generated in a PMS-NADH system. The scavenging activity of alkyl gallates for superoxide anion decreased as the alkyl side chain length increased. Differences in superoxide anion scavenging activity among alkyl gallates may be explained by the fact that an alkyl gallate with a shorter alkyl chain is a smaller molecule and more water soluble which allows it to easily react with the superoxide anion. However an alkyl gallate with a long alkyl chain hardly reacts with superoxide anion at low concentration but rapidly reacts at concentrations higher than $100 \mu \mathrm{M}$. It may explain that at low concentration alkyl gallate with a longer chain is less water soluble to hardly react with superoxide anion but at high concentration the amphipathic gallate aggregates to form a micelle which dissolves the components of the PMS-NADH system and the gallate in the micelles easily scavenges superoxide anion generated from the system [38].

Effects of gallic acid and alkyl gallates on superoxide anion generation were examined under limited concentration of gallates to exclude influence of their scavenging activities. All gallates inhibited superoxide anion generation (Table $\mathbf{3}$ ), and the inhibition did not depend on alkyl chain length of gallates. It suggested that inhibition of superoxide anion generation with gallic acid and alkyl gallates having a short alkyl chain did not correspond to that of xanthine oxidase reaction itself. To confirm stoichiometry of xanthine oxidase reaction, oxygen consumption and hydrogen peroxide formation of the reaction were examined. No inhibition of oxygen consumption with gallic acid was observed, and the inhibition with alkyl gallates having a long chain was consistent with that of uric acid formation. No inhibition of hydrogen peroxide formation with gallic acid was also indicated.
These results confirmed that gallic acid and alkyl gallates having short alkyl chain inhibited superoxide anion generation without inhibition of xanthine oxidase reaction.

Table 3. Kinetic Parameters of Gallic Acid and Its Alkyl Esters for Superoxide Anion Generation by Xanthine Oxidase ${ }^{\text {a) }}$

\begin{tabular}{|c|c|c|c|}
\hline \multirow{2}{*}{ Gallates Tested } & \multirow{2}{*}{$\mathbf{I C}_{50}(\boldsymbol{\mu} \mathbf{M})^{\mathbf{b})}$} & \multicolumn{2}{|c|}{ For Xanthine-Binding $(\boldsymbol{\mu} \mathbf{M})$} \\
\cline { 3 - 4 } & & $\boldsymbol{K}_{\mathbf{I}}$ & $\boldsymbol{K}_{\mathrm{IS}}$ \\
\hline \hline Gallic acid (1) & $2.6 \pm 0.3$ & $1.5 \pm 0.2$ & $2.9 \pm 0.3$ \\
\hline $\mathrm{C}_{1}(\mathbf{2})$ & $7.4 \pm 0.5$ & $5.7 \pm 0.4$ & $8.0 \pm 0.6$ \\
\hline $\mathrm{C}_{3}(\mathbf{3})$ & $6.4 \pm 1.0^{\mathrm{c})}$ & $4.5 \pm 0.5$ & $6.8 \pm 0.7$ \\
\hline $\mathrm{C}_{6}(\mathbf{4})$ & $5.2 \pm 0.2^{\mathrm{c})}$ & $3.8 \pm 0.4$ & $5.3 \pm 0.6$ \\
\hline $\mathrm{C}_{8}(\mathbf{5})$ & $4.5 \pm 0.5^{\mathrm{c}}$ & $3.9 \pm 0.2$ & $4.7 \pm 0.2$ \\
\hline $\mathrm{C}_{10}(\mathbf{7})$ & $3.9 \pm 1.1^{\mathrm{c})}$ & $2.5 \pm 0.6$ & $4.8 \pm 1.0$ \\
\hline $\mathrm{C}_{12}(\mathbf{9})$ & $3.6 \pm 0.2^{\mathrm{c})}$ & $1.8 \pm 0.2$ & $4.4 \pm 0.2$ \\
\hline Menthyl(14) & $4.9 \pm 1.3^{\mathrm{c})}$ & $2.6 \pm 0.4$ & $4.9 \pm 0.8$ \\
\hline Bornyl $(\mathbf{1 5})$ & $6.4 \pm 1.0^{\mathrm{c})}$ & $4.5 \pm 0.3$ & $6.3 \pm 0.4$ \\
\hline
\end{tabular}

a) Xanthine oxidase reaction was carried out at $0-200 \mu \mathrm{M}$ xanthine in the presence of $0.0,0.5,1.0$ and $2.0 \mu \mathrm{M}$ of gallic acid or alkyl gallates under air atmosphere. Values were expressed as mean \pm SD obtained from more than three separate experiments.

${ }^{\text {b) }} \mathrm{IC}_{50}$ values were indicated at $200 \mu \mathrm{M}$ xanthine.

c) The value was estimated.

Xanthine oxidase-catalyzed reaction of oxygen to superoxide anion is known to proceed at the FAD-binding domain [37]. The binding site in the FAD-binding domain is considerably hydrophilic, and structure of the site is similar to that of vanillyl alcohol oxidase [39], of which the isoalloxazine ring binds to a wide range of phenolic substrates. Compounds with a galloyl moiety bound to the isoalloxazine ring of $\mathrm{FADH}_{2}$ in squalene epoxidase [40]. As octyl, decyl and dodecyl gallates were predominantly competitive inhibitors of oxygen for uric acid formation and gallic acid and alkyl gallates equally inhibited superoxide anion generation, we deduced that galloyl moiety of gallic acid and alkyl gallates bound superoxide generation site in FAD-binding domain of xanthine oxidase. Binding of gallic acid and alkyl gallates to $\mathrm{FADH}_{2}$ in the enzyme can easily reduce the enzyme, xan- 


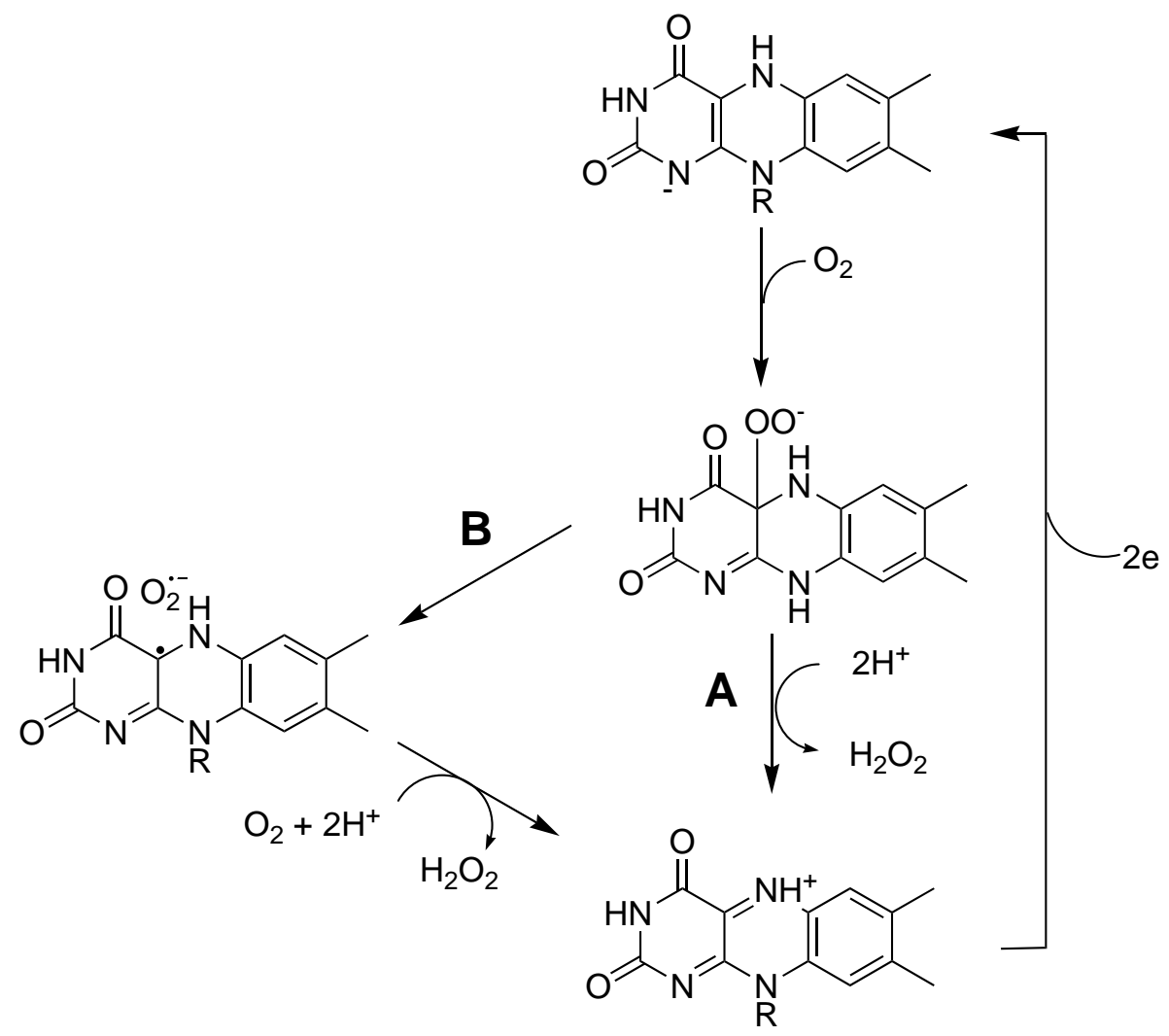

Fig. (8). Proposed mechanism of hydrogen peroxide formation by xanthine oxidase in the presence of gallic acid or alkyl gallates. Binding of gallates to the isoalloxazine ring in $\mathrm{FADH}_{2}$ reduces the enzyme, xanthine oxidase. $\mathrm{FADH}_{2}$ in the enzyme reduces oxygen to the flavin hydroperoxide and the hydroperoxide is smoothly reduced to hydrogen peroxide (A pathway).

thine oxidase, and cannot prevent the binding of the first oxygen molecule to the site since oxygen is so small and reactive. We propose that $\mathrm{FADH}_{2}$ in the reduced oxidase smoothly reduces first oxygen molecule to hydrogen peroxide (A pathway) rather than reducing the second oxygen molecule to superoxide anion (B pathway) as shown in Fig. (8).

\subsection{Chelation of Transition Metal Ions}

Alkyl gallates are known to chelate transition metal ions which are powerful promoters of free radical damage in foods [41]. Alkyl gallates may suppress the superoxidederived Fenton reaction, which is currently believed to be the most important route to active oxygen species [42]. Thus, metal chelation may play a large role in determining the antioxidant activity [43]. The chelation ability, rendering the metal ions inactive to participate in free radical generating reactions, demonstrates the considerable advantage of alkyl gallates as antioxidants.

After the alkyl gallates are consumed together with the foods to which they are added as additives, these alkyl gallates are hydrolyzed to the original gallic acid and the corresponding alcohols. Hence, benefits to human health after consumption of alkyl gallates needs to be concerned mainly with gallic acid. Lipid peroxidation is known to be one of the reactions set into motion as a consequence of the formation of free radicals in cells and tissues. Membrane lipids are abundant in unsaturated fatty acids. The free gallic acid still acts as a potent antioxidant in a living system. Lipoxygenases are suggested to be involved in the early event of atherosclerosis by inducing plasma low-density lipoprotein (LDL) oxidation [44, 45]. However, gallic acid did not inhibit the linoleic acid peroxidation catalyzed by soybean lipoxygenase-1, indicating that alkyl side chain is essential to elicit the activity. On the other hand, gallic acid was found as the most effective in scavenging superoxide anion generated by xanthine oxidase.

\section{DISCUSSION}

The major antioxidants are metal chelators and chainbreaking agents acting as hydrogen atom donors [46]. By selecting gallic acid as a head portion, both potent scavenging activity and chelation of metals can be added in general regardless of the hydrophobic tail portion. Alkyl gallates such as octyl- and dodecyl-gallates are powerful antioxidative and antimicrobial agents [4, 18, 20, 21, 47-49]. This concept was further extended to geranyl gallate (17) since geraniol is reported to increase glutathione $S$-transferase activity, which is believed to be a major mechanism for chemical carcinogen detoxification [50]. As expected, geranyl gallate exhibited activity against $S$. choleraesuis, with a maximum bactericidal concentration (MBC) of $50 \mu \mathrm{g} / \mathrm{mL}$. In this connection, geraniol is found in a large number $(>160)$ of essential oils - such as lemon grass, coriander, lavender and carrot - and is used as food flavoring for baked goods, soft and hard candy, gelatin and pudding, and chewing gum. The antioxidant gallic acid and the glutathion $S$-transferase inducer geraniol may contribute to reduce cancer risk as well as oxidative damage-related diseases. Antioxidant activity of alkyl gallates was emphasized for food protection but they 
are equally potent antioxidants in other applications such as cosmeceutical applications. For example, antioxidative antimicrobial agents, octyl- and dodecyl-gallates, were previously reported to inhibit steroid $5 \alpha$-reductase [51]. This inhibitory activity is not related to food protection but they also have the potent lipoxygenase inhibitory activity and the antibacterial activity against Propionibacterium acnes. These gallates can be considered for external use as acne control agents [52]. As an ideal multifunctional agent, both lipoxygenase- 1 inhibitory and antimicrobial activities need to be elicited at the same concentration. However, the antimicrobial activity of octyl gallate requires higher concentrations compared to its soybean lipoxygenase-1 inhibitory activity. For example, the maximum fungicidal concentrations (MFCs) against three food related fungi, Saccharomyces cerevisiae, Zygosaccharomyces bailii and Aspergillus niger are 89,177 and $355 \mu \mathrm{M}$, respectively [20].

Gallic acid is known to chelate transition metal ions which are powerful promoters of free radical damage in the human body [53]. More specifically, alkyl gallates may prevent cell damage induced by hydrogen peroxide $\left(\mathrm{H}_{2} \mathrm{O}_{2}\right)$ since this can be converted to the more reactive oxygen species, hydroxyl radicals in the presence of these metal ions. In fact, gallic acid was described to scavenge hydrogen peroxide and to inhibit lipid peroxidation [54]. In connection with this, catechol groups also have iron binding properties in vitro. However, the inhibition of iron absorption in vivo was positively correlated with the presence of galloyl group but not catechol group [55]. The nitric oxide (NO·), a free radical species produced by several mammalian cell types, plays a role in regulation and function. NO toxicity is mainly mediated by peroxynitrite $\left(\mathrm{ONOO}^{-}\right)$, formed in the reaction of $\mathrm{NO}$ with $\mathrm{O}_{2} \cdot{ }^{-}[56]$. Gallic acid was previously reported to act as a potent peroxynitrite scavenger [57] and to show antiproliferative activity against melanocytes cell lines [58]. Sulfonation is one of the major phase II conjugative reactions involved in the biotransformation of various endogenous compounds, drugs, and xenobiotics as well as in steroid biosynthesis, catecholamine metabolism, and thyroid hormone homeostasis [59]. Gallic acid enhanced the activity of phenolsulfotransferase and exhibited antioxidant activity as determined by the oxygen radical absorbance capacity assay and Trolox equivalent antioxidant capacity assay [60]. Gallic acid was recently described to activate microsomal glutathione $S$-transferase through oxidative modification of the enzyme [61]. Despite the advantages summarized, biological significance of gallic acid as an antioxidant in living systems is still largely unknown. Thus, it is not clear if gallic acid is absorbed into the system without being metabolized and delivered to the places where an antioxidant is needed. The relevance of the in vitro experiments in simplified systems to in vivo protection from oxidative damage should be carefully considered.

Finally, the possibility that gallic acid's adverse effects are a consequence of its potential to act as a prooxidant may need to be considered. Gallic acid and its esters were described to induce apoptosis in human leukemia HL60 RG and to show cytotoxic effects on other cell lines [62 - 65]. In these apoptotic processes, the generation of ROS (reactive oxygen species) is thought to contribute in the initiation of apoptosis [62, 66, 67]. In fact, gallic acid is known to produce superoxide anion [1]. On the other hand, alkyl gallates are known to protect the cell damage induced by hydroxy radicals and hydrogen peroxides against dermal fibroblast cells and this protective effect is dependent on the alkyl chain length [68]. The biological activities of gallic acid seem to depend upon its behavior as either an antioxidant or a prooxidant [69]. Thus the relevance of the in vitro experiments in simplified systems should be carefully considered. The results so far obtained indicate that their further evaluation is needed from not only one aspect, but from a whole and dynamic perspective.

\section{MATERIALS AND METHODS}

\section{Chemicals}

Alkyl gallates were available from our previous works [4, 70]. 1,1-Diphenyl-2-picrylhydrazyl (DPPH), L-DOPA and methanol were purchased from Aldrich Chemical Co. (Milwaukee, WI). Dimethyl sulfoxide (DMSO), EDTA, Tween-20, bovine serum albumin and linoleic acid (purity $>99 \%$ ) were purchased from Sigma Chemical Co. (St. Louis, MO). Tris buffer was obtained from Fisher Scientific Co. (Fair Lawn, NJ). Ethanol was purchased from Quantum Chemical Co. (Tuscola, IL).

\section{DPPH Radical Scavenging Assay}

First, $1 \mathrm{~mL}$ of $100 \mathrm{mM}$ acetate buffer (pH 5.5), $1.87 \mathrm{~mL}$ of ethanol and $0.1 \mathrm{~mL}$ of ethanolic solution of $3 \mathrm{mM} \mathrm{DPPH}$ were put into a test tube. Then, $0.03 \mathrm{~mL}$ of the sample solution (dissolved in DMSO) was added to the tube and incubated at $25{ }^{\circ} \mathrm{C}$ for $20 \mathrm{~min}$. The absorbance at $517 \mathrm{~nm}$ (DPPH, $\varepsilon=8.32 \times 10^{3} \mathrm{M}^{-1} \mathrm{~cm}^{-1}$ ) was recorded. As a control, $0.03 \mathrm{~mL}$ of DMSO without sample was added to a tube. From decrease of the absorbance, scavenging activity was calculated and expressed as scavenged DPPH molecules per a test molecule.

\section{Lipoxygenase Assay}

Throughout the experiment, linoleic acid was used as a substrate. In spectophotometric experiment, the oxygenase activity of the soybean lipoxygenase was monitored at $25{ }^{\circ} \mathrm{C}$ by Spectra MAX plus spectrophotometer (Molecular device, Sunnyvale, CA). 13-Hydroperoxyoctadecadienoic acid (13-HPOD: $\lambda_{\max }=234 \mathrm{~nm}, \varepsilon=25 \mathrm{mM}^{-1} \mathrm{~cm}^{-1}$ ) was prepared enzymatically by described procedure [71] and stored in ethanol at $-18{ }^{\circ} \mathrm{C}$. Commercial lipoxygenase contains a nonheme ferrous ion $\left(E_{\mathrm{red}}\right)$ that must be oxidized to yield the catalytically active ferric enzyme $\left(E_{\mathrm{ox}}\right)$ and therefore a catalytic amount of LOOH (13-HPOD) is usually added as a cofactor to LH (linoleic acid, a substrate). Alkyl gallates chelate both ferric and ferrous ions.

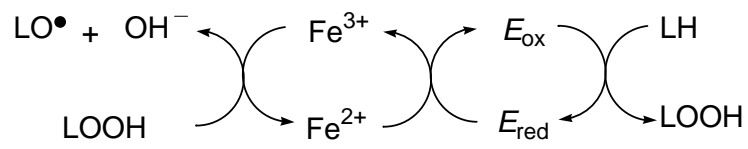

The enzyme assay was performed as previously reported [72] with slight modification. In general, $5 \mu \mathrm{L}$ of an ethanolic inhibitor solution was mixed with $54 \mu \mathrm{L}$ of $1 \mathrm{mM}$ stock solution of linoleic acid and $2.936 \mathrm{~mL}$ of $0.1 \mathrm{M}$ Tris- $\mathrm{HCl}$ buffer ( $\mathrm{pH} 8.0)$ in a quartz cuvet. Then, $5 \mu \mathrm{L}$ of $0.1 \mathrm{M}$ Tris- 
$\mathrm{HCl}$ buffer solution ( $\mathrm{pH} 8.0)$ of lipoxygenase $(1.02 \mu \mathrm{M})$ was added. The resultant solution was mixed well and the linear increase of absorbance at $234 \mathrm{~nm}$, which express the formation of conjugated diene hydroperoxide (13-HPOD), was measured continuously. Lag period shown on lipoxygenase reaction [73] was excluded for the determination of initial rates. The stock solution of linoleic acid was prepared with methanol and Tris- $\mathrm{HCl}$ buffer at $\mathrm{pH} 8.0$, and, then, total methanol content in the final assay was adjusted below $1.5 \%$.

To determine the kinetic parameters associated with slow-binding inhibition of soybean lipoxygenase-1, progress curves with 25 or more data points $(\leq 300)$, typically at 2 second intervals, were obtained at several inhibitor concentrations and fixed concentration of substrate. The data were analyzed using the nonlinear regression program of Sigma Plot (SPSS Inc., Chicago, IL) to give the individual parameters for each progress curve; $v_{\mathrm{i}}$ (initial velocity), $v_{\mathrm{s}}$ (steadystate velocity), $k_{\mathrm{obs}}$ (apparent first-order rate constant for the transition from $v_{\mathrm{i}}$ to $v_{\mathrm{s}}$ ), $A$ (absorbance at $234 \mathrm{~nm}$ and/or $\mathrm{O}_{2}$ uptake), $A_{0}$ (included to correct any possible deviation of the baseline), and $K_{\mathrm{i}}^{\text {app }}$ (apparent $K_{\mathrm{i}}$ ) according to eq 1 and 2 [74]:

$A=v_{\mathrm{s}} \mathrm{t}+\left(v_{\mathrm{i}}-v_{\mathrm{s}}\right)\left[1-\exp \left(-k_{\mathrm{obs}} \mathrm{t}\right)\right] / k_{\mathrm{obs}}+A_{0}$

$k_{\text {obs }}=k_{6}+\left[\left(k_{5} \times[\mathrm{I}]\right) /\left(K_{\mathrm{i}}^{\mathrm{app}}+[\mathrm{I}]\right)\right]$

\section{Assay of Superoxide Anion Generated by Xanthine Oxidase}

Xanthine oxidase (EC 1.1.3.22, Grade IV) was purchased from Sigma Chemical Co. Superoxide anion was generated enzymatically by xanthine oxidase system. The reaction mixture consisted of $2.70 \mathrm{~mL}$ of $40 \mathrm{mM}$ sodium carbonate buffer containing $0.1 \mathrm{mM}$ EDTA (pH 10.0), $0.06 \mathrm{~mL}$ of 10 $\mathrm{mM}$ xanthine, $0.03 \mathrm{~mL}$ of $0.5 \%$ bovine serum albumin, 0.03 $\mathrm{mL}$ of $2.5 \mathrm{mM}$ nitroblue tetrazolium and $0.06 \mathrm{~mL}$ of sample solution (dissolved in DMSO). To the mixture at $25^{\circ} \mathrm{C}, 0.12$ $\mathrm{mL}$ of xanthine oxidase ( 0.04 units) was added, and the absorbance at $560 \mathrm{~nm}$ was recorded for $90 \mathrm{sec}$ (by formation of blue formazan) [74]. Control experiment was carried out by replacing sample solution with same amount of DMSO.

\section{Uric Acid Generated by Xanthine Oxidase}

The reaction mixture consisted of $2.76 \mathrm{~mL}$ of 40 $\mathrm{mM}$ sodium carbonate buffer containing $0.1 \mathrm{mM}$ EDTA (pH 10.0), $0.06 \mathrm{~mL}$ of $10 \mathrm{mM}$ xanthine and $0.06 \mathrm{~mL}$ of sample solution (dissolved in DMSO). The reaction was started by the addition of $0.12 \mathrm{~mL}$ of xanthine oxidase (0.04 Unit), and the absorbance at $293 \mathrm{~nm}$ was recorded for $90 \mathrm{sec}$. In the case of dodecyl gallate, the concentration of DMSO was increased to $8 \%$ because of the low solubility of dodecyl gallate in the reaction mixture. It should be noted that the measurement of xanthine oxidase inhibitory activity was possible only for concentrations $<0.2 \mathrm{mM}$ due to overlapping absorbance of alkyl gallates and uric acid at 293 $\mathrm{nm}$.

\section{ACKNOWLEDGEMENTS}

The work was presented in part at the Symposium of Diet and the Prevention of Gender Related Cancers in Division of Agricultural and Food Chemistry for the 222nd ACS
National Meeting in Chicago, Il. The authors are grateful to Dr. H. Haraguchi for performing autoxidation assay at earlier stage of the work.

\section{REFERENCES}

[1] Serrano, A.; Palacios, C.; Roy, G.; Cespon, C.; Villar, M. L.; Nocito, M.; Gonzalez-Porque, P. Derivatives of gallic acid induce apoptosis in tumoral cell lines and inhibit lymphocyte proliferation. Arch. Biochem. Biophys., 1998, 350, 49-54.

[2] Huang, D.; Ou, B.; Prior, R. The chemistry behind antioxidant capacity assays. J. Agric. Food Chem., 2005, 53, 1841-1856.

[3] Aruoma, O.I.; Murcia, A.; Butler, J.; Halliwell, B. Evaluation of the antioxidant and prooxidant actions of gallic acid and its derivatives. J. Agric. Food Chem., 1993, 41, 1880-1885.

[4] Kubo, I.; Xiao, P.; Nihei, K.; Fujita, K.; Yamagiwa, Y.; Kamikawa, T. Molecular design of antifungal agents. J. Agric. Food Chem., 2002, 50, 3992-3998.

[5] Kubo, I.; Chen, Q. X.; Nihei, K. Molecular design of antibrowning agents: Antioxidative tyrosinase inhibitors. Food Chem., 2003, 81, 241-247.

[6] Gray, J.I.; Pearson, A.M. Rancidity and warmed-over flavor. Avd. Meat Res., 1987, 3, 221-269.

[7] Faustman, C.; Cassens, R.G.; Schaefer, D.M.; Buege, D.R.; Williams, S.N.; Scheller, K.K. Improvement of pigment and lipid stability in Holstein steer beef by dietary supplementation with vitamin E. J. Food Sci., 1989, 54, 858-862.

[8] Monahan, F.J.; Gray, J.I.; Booren, A.M.; Miller, E.R.; Buckley, D.J.; Morrissey, P. A.; Gomaa, E. A. Influence of dietary treatment on cholesterol oxidation in pork, J. Agric. Food Chem., 1992, 40, 1310-1315.

[9] Tsuda, T.; Ohshima, K.; Kawakishi, S.; Osawa, T. Antioxidative pigments isolated from the seeds of Phaseolus vulgaris L. J. Agric. Food Chem., 1994, 42, 248-251.

[10] Machlin, L.; Bendich, A. Free radical tissue damage: protective role of antioxidant nutrients. FASEB J., 1987, 1, 441-445.

[11] Slater, T.F.; Cheeseman, K.H. Free radical mechanisms in relation to tissue injury. Proc. Natr. Soc., 1987, 46, 1-12.

[12] Sugawara, H.; Tobise, K.; Minami, H.; Uekita, K.; Yoshie, H.; Onodera, S. Diabetes mellitus and reperfusion injury increase the level of active oxygen-induced lipid peroxidation in rat cardiac membranes. J. Clin. Exp. Med., 1992, 163, 237-238.

[13] Kok, F.J.; Van Poppel, G.; Melse, J.; Verheul, E.; Schouten, E.G.; Kruyssen, D.H.C.M.; Hofman, A. Do antioxidants and polyunsaturated fatty acids have a combined association with coronary arteriosclerosis? Arteriosclerosis, 1991, 86, 85-90.

[14] Yagi, K. Lipid peroxides and human disease. Chem. Phys. Lipid, 1987, 45, 337-341.

[15] Yoshida, T.; Mori, K.; Hatano, T.; Okamura, T.; Uehara, I.; Komagoe, K.; Fujita, Y.; Okuda, T. Studies on inhibition mechanism of autoxidation by tannins and flavonoids. V. Radical-scavenging effects of tannins and related polyphenols on 1,1-diphenyl-2picrylhydrazyl radical. Chem. Pharm. Bull., 1989, 37, 1919-1921.

[16] Savi, L.A.; Leal, P.C.; Vieira, T.O.; Rosso, R.; Nunes, R.J.; Yunes, R.A.; Creczynski-Pasa, T.B.; Barardi, C.R.M.; Simões, C.M.O. Evaluation of anti-herpetic and antioxidant activities, and cytotoxic and genotoxic effects of synthetic alkyl-esters of gallic acid. Arztl. Forsch., 2005, 55, 66-75.

[17] Gunckel, S.; Santander, P.; Cordano, G.; Ferreira, J.; Munoz, S.; Nunez-Vergara, L.J.; Squella, J.A.. Antioxidant activity of gallates: an electrochemical study in aqueous media. Chem. Biol. Inter. 1998, 114, 45-59.

[18] Kubo, I.; Xiao, P.; Fujita, K. Antifungal activity of octyl gallate: Structural criteria and mode of action. Bioorg. Med. Chem. Lett., 2001, 11, 347-350.

[19] Fujita, K.; Kubo, I. Plasma membrane injury by nonyl gallate in Saccharomyces cerevisiae. J. Appl. Microbiol., 2002, 92, 10351042.

[20] Fujita, K.; Kubo, I. Antifungal activity of octyl gallate. Int. J. Food Microbiol., 2002, 79, 193-201.

[21] Kubo, I.; Fujita, K.; Nihei, K.; Masuoka, N. Non-antibiotic antibacterial activity of dodecyl gallate. Bioorg. Med. Chem., 2003, 11, 573-580. 
[22] Rice-Evans, C.A.; Miller, N.J.; Paganga, G. Structure-antioxidant activity relationships of flavonoids and phenolic acid. Free Radic. Biol. Med., 1996, 20, 933-956.

[23] Grechkin, A. Recent developments in biochemistry of the plant lipoxygenase pathway. Prog. Lipid Res., 1998, 37, 317-352.

[24] Min, B.; Ahn, D.U. Mechanism of lipid peroxidation in meat and meat products - A review. Food Sci. Biotechnol., 2005, 14, 152-163.

[25] Witting, L.A. Vitamin E and lipid antioxidants in free-radicalinitiated reactions. Pryor, W. A., Ed. In Free Radicals in Biology, Academic Press: New York, 1980; Vol. 4, pp. 295-319.

[26] Haraguchi, H.; Hashimoto, K.; Yagi, A. Antioxidative substances in leaves of Polygonum hydropiper. J. Agric. Food Chem., 1992, 40, 1349-1351.

[27] Shibata, D.; Axelrod, B. Plant lipoxygenases. J. Lipid Mediat. Cell Signal., 1995, 12, 213-228.

[28] Richard-Forget, F.; Gauillard, F.; Hugues, M.; Jean-Marc, T.; Boivin, P.; Nicolas, J. Inhibition of horse bean and germinated barley lipoxygenases by some phenolic compounds. J. Food Sci., 1995, 60, 1325-1329.

[29] Grechkin, A. Recent developments in biochemistry of the plant lipoxygenase pathway. Prog. Lipid Res., 1998, 37, 317-352.

[30] Axelrod, B.; Cheesbrough, T.M.; Laakso, S. Lipoxygenase from soybeans. Methods Enzymol., 1981, 71, 441-457.

[31] Ha, T.J.; Nihei, K.; Kubo, I. Lipoxygenase inhibitory activity of octyl gallate. J. Agric. Food Chem., 2004, 52, 3177-3181

[32] Whitman, S.; Gezginci, M.; Timmermann, B.; Holman, T.R. Structure-activity relationship studies of nordihydroguaiaretic acid inhibitors toward soybean, 12-human, and 15-human lipoxygenase. J. Med. Chem., 2002, 45, 2659-2661.

[33] Ruddat, V.C.; Whitman, S.; Holman, T.R.; Bernasconi, C.F. Stopped-flow kinetics investigations of the activation of soybean lipoxygenase-1 and the influence of inhibitors on the allosteric site. Biochemistry, 2003, 42, 4172-4178.

[34] Grunfeld, S.; Hamilton, C.A.; Mesaros, S.; McClain, S.W.; Dominiczak, A.F.; Bohr, D.F.; Malinski, T. Rple of superoxide in the depressed nitric oxide production by the endothelium of genetically hypertensive rats. Hepertension, 1995, 26, 854-857.

[35] Hille, R.; Massey, V. Studies on the oxidative half-reaction of xanthine oxidase. J. Biol. Chem., 1981, 256, 9090-9095.

[36] Masuoka, N.; Nihei, K.; Kubo, I. Xanthine oxidase inhibitory activity of alkyl gallates. Mol. Nutr. Food Sci., 2006, 50, 725-731.

[37] Enroth, C.; Eger, B.T.; Okamoto, K.; Nishino, T.; Pai, E.F. Crystal structures of bovine milk xanthine dehydrogenase and xanthine oxidase: Structure-based mechanism of conversion. Proc. Nat. Acad. Sci., 2000, 97, 10723-10728.

[38] McGovern, S.L.; Caselli, E.; Grigorieff, N.; Shoichet, B.K. A common mechanism underlying promiscuous inhibitors from virtual and high-throughput screening, J. Med. Chem., 2002, 45, 1712-1722.

[39] Fraaiji, M.W.; van den Heuvel, R.H.H.; van Berkel, W.J.H.; Mattevi, A. Structural analysis of flavinylation in vanillyl-alcohol oxidase. J. Biol. Chem., 2000, 275, 38654-38658

[40] Abe, I.; Seki, T.; Noguchi, H. Potent and selective inhibition of squalene epoxidase by synthetic galloyl esters. Biochem. Biophys. Res. Commun., 2000, 270, 137-140.

[41] Aruoma, O.I.; Halliwell, B. DNA damage and free radicals. Chem. Brit., 1991, 27, 149-150

[42] Afanas'ev, I.; Dorozhko, A.I.; Brodskii, A.V.; Kostyul, V.A.; Potapovitch, A.I. Chelating and free radical scavenging mechanisms of inhibitory action of rutin and quercetin in lipid peroxidation. Biochem. Pharmacol., 1989, 38, 1763-1769.

[43] Arora, A.; Nair, M.G.; Strasburg, G.M. Structure-activity relationships for antioxidant activities of a series of flavonoids a liposomal system. Free Rad. Biol. Med., 1998, 24, 1355-1363.

[44] Cornicelli, J.A.; Trivedi, B.K. 15-Lipoxygenase and its inhibition: a novel therapeutic target for vascular disease. Curr. Pharm. Des., 1999, 5, 11-20.

[45] Kris-Etherton, P.M.; Keen, C.L. Evidence that the antioxidant flavonoids in tea and cocoa are beneficial for cardiovascular health. Curr. Opin. Lipidol., 2002, 13, 41-49.

[46] Huang, D.; Ou, B.; Prior, R. The chemistry behind antioxidant capacity assays. J. Agric. Food Chem., 2005, 53, 1841-1856.
[47] Kubo, I.; Xiao, P.; Fujita, K. Anti-MRSA activity of akyl gallates. Bioorg. Med. Chem. Lett., 2002, 12, 113-116.

[48] Kubo, I.; Fujita, K.; Nihei, K. Anti-Salmonella activity of alkyl gallates. J. Agric. Food Chem., 2002, 50, 6692-6696.

[49] Kubo, I.; Fujita, K.; Nihei, K.; Nihei, A. Antibacterial activity of alkyl gallates against Bacillus subtilis. J. Agric. Food Chem., 2004, 52, 1072-1076.

[50] Zheng, G.Q.; Kenney, P.M.; Lam, L.K. Potential anticarcinogenic natural products isolated from lemongrass oil and galanga root oil. J. Agric. Food Chem., 1993, 41, 153-156.

[51] Hiipakka, R.A.; Zhang, H.Z.; Dai, W.; Dai, Q.; Liao, S. Structureactivity relationship for inhibition of human $5 \alpha$-reductase by polyphenols. Biochem. Pharmacol., 2002, 63, 1165-1176.

[52] Zouboulis, C.C.; Piquero-Martin, J. Update and future of systemic treatment. Dermatology, 2003, 206, 37-53.

[53] Henle, E.S.; Linn, S. Formation, prevention, and repair of DNA damage by iron/hydrogen peroxide. J. Biol. Chem., 1997, 272, 19095-19098

[54] Sroka, Z.; Cisowski, W. Hydrogen peroxide scavenging, antioxidant and anti-radical activity of some phenolic acids. Food Chem. Toxicol., 2003, 41, 753-758.

[55] Brune, M.; Rossander, L.; Hallberg, L. Iron absorption and phenolic compound: Importance of different phenolic structures. Eur. $J$. Clin. Nutr., 1989, 43, 547-558.

[56] Rubbo, H.; Darley-Usmar, V.; Freeman, B.A. Nitric oxide regulation of tissue free radical injury. Chem. Res. Toxicol., 1996, 9, 809820 .

[57] Heijnen, C.G.M.; Haenen, G.R.M.M.; Vekemans, J.A.J.M.; Bast, A. Peroxynitrite scavenging of flavonoids: structure activity relationship. Envirom. Toxicol. Pharmacol., 2001, 10, 199-206.

[58] Yáñez, J.; Vicente, V.; Alcaraz, M.; Castillo, J.; Benavente-García, O.; Canteras, M.; Lozano, T.J.A. Cytotoxicity and antiproliferative activities of several phenolic compounds against three melanocytes cell lines: relationship between structure and activity. Nutr. Cancer, 2004, 49, 191-199.

[59] Brix, L.A.; Nicoll, R.; Zhu, X.; McManus, M.E. Structural and functional characterization of human sulfotransferases. Chem. Biol. Inter., 1998, 109, 123-127.

[60] Yeh, C.T.; Yen, G.C. Effects of phenolic acids on human phenolsulfotransferases in relation to their antioxioxidant activity. $J$. Agric. Food Chem., 2003, 51, 1474-1479.

[61] Shinno, E.; Shimoji, M.; Imaizumi, N.; Kinoshita, S.; Sunakawa, H.; Aniya, Y. Activation of rat liver microsomal glutathione Stransferase by gallic acid. Life Sci., 2005, 78, 99-106.

[62] Inoue, M.; Suzuki, R.; Koide, T.; Sakaguchi, N.; Ogihara, Y.; Yabe, Y. Antioxidant, gallic acid, induced apoptosis in HL-60RG cells. Biochem. Biophys. Res. Commun., 1994, 204, 898-904.

[63] Sakaguchi, N.; Inoue, M.; Isuzugawa, K.; Ogihara, Y.; Hosaka, K. Cell death-inducing activity by gallic acid derivatives. Biol. Pharm. Bull., 1999, 22, 471-475.

[64] Ohno, Y.; Fukuda, K.; Takemura, G.; Toyota, M.; Watanabe, M.; Yasuda, N.; Xinbin, Q.; Maruyama, R.; Akao, S.; Gotou, K.; Fujiwara, T.; Fujiwara, H. Induction of apoptosis by gallic acid in lung cancer cells. Anticancer Drugs, 1999, 10, 845-851.

[65] Yoshioka, K.; Kataoka, T.; Hayashi, T.; Hasegawa, M.; Ishii, Y.; Hibasami, H. Induction of apoptosis by gallic acid in human stomach cancer KATO III and colon adenocarcinoma COLO 205 cell lines. Oncol. Rep., 2000, 7, 1221-1223.

[66] Sakaguchi, N.; Inoue, M.; Ogihara, Y. Reactive oxygen species and intracellular $\mathrm{Ca}^{2+}$, common signals for apoptosis induced by gallic acid. Biochem. Pharm., 1998, 55, 1973-1981.

[67] Isuzugawa, K.; Inoue, M.; Ogihara, Y. Catalase contents in cells determine sensitivity to the apoptosis inducer gallic acid. Biol. Pharm. Bull., 2001, 24, 1022-1026.

[68] Masaki, H.; Okamoto, N.; Sakai, S.; Sakurai, H. Protective effects of hydroxybenzoic acids and their esters on cell damage induced by hydroxyl radicals and hydrogen peroxides. Bull. Pharm. Bull., 1997, 20, 304-308

[69] Yen, G.C.; Duh, P.D.; Tsai, H.L. Antioxidant and pro-oxidant properties of ascorbic acid and hallic acid. Food Chem., 2002, 79, 307-313 
[70] Nihei, K.; Nihei, A.; Kubo, I. Molecular design of multifunctional food additives. Antioxidative antifungal agents. J. Agric. Food Chem., 2004, 52, 5011-5020.

[71] Gibian, M.J.; Galaway, R.A. Steady-state kinetics lipoxygenase oxygenation of unsaturated fatty acid. Biochemistry, 1976, 15, 4209-4214.

[72] Ruddat, V.C.; Whitman, S.; Holman, T.R.; Bernasconi, C.F. Stopped-flow kinetics investigations of the activation of soybean lipoxygenase-1 and the influence of inhibitors on the allosteric site. Biochemistry, 2003, 42, 4172-4178.

[73] Frieden, C. Kinetic aspects of regulation of metabolic processes. The hysteretic enzyme concept. J. Biol. Chem., 1970, 245, 57885799.

[74] Toda, S.; Kumura, M.; Ohnishi, M. Effects of phenolcarboxylic acids on superoxide anion. Planta Med., 1991, 57, 8-10.

(C) Kubo et al.; Licensee Bentham Open.

This is an open access article licensed under the terms of the Creative Commons Attribution Non-Commercial License (http://creativecommons.org/licenses/by$\mathrm{nc} / 3.0 /$ ) which permits unrestricted, non-commercial use, distribution and reproduction in any medium, provided the work is properly cited. 